\title{
LOW PRESSURE CARBURIZING IN A LARGE-CHAMBER DEVICE FOR HIGH-PERFORMANCE AND PRECISION THERMAL TREATMENT OF PARTS OF MECHANICAL GEAR
}

\author{
Emilia Wołowiec-Korecka', Maciej Korecki ${ }^{2}$, Leszek Klimek', \\ Piotr Kula', Agnieszka Brewka ${ }^{3}$, Magdalena Buczek' \\ 1 Instytut Inżynierii Materiałowej, Politechnika Łódzka, Stefanowskiego 1/15, 90-924 Łódź, Poland, e-mail: \\ emilia.wolowiec@p.lodz.pl, leszek.klimek@p.lodz.pl, magda.buczek@onet.pl \\ 2 Seco/Warwick SA, Sobieskiego 8, 66-200 Świebodzin, Poland, e-mail: maciej.korecki@secowarwick.com \\ 3 Seco/Warwick Europe, Świerczewskiego 76, 66-200 Świebodzin, Poland, e-mail: agnieszka.brewka@ \\ secowarwick.com
}

Received: 2016.12 .15

Accepted: 2017.02.01

Published: 2017.03.01

\begin{abstract}
This paper presents the findings of research of a short-pulse low pressure carburizing technology developed for a new large-chamber furnace for high-performance and precision thermal treatment of parts of mechanical gear. Sections of the article discuss the novel constructions of the device in which parts being carburized flow in a stream, as well as the low-pressure carburizing experiment. The method has been found to yield uniform, even and repeatable carburized layers on typical gear used in automotive industry.
\end{abstract}

Keywords: heat treatment, vacuum carburizing, lean manufacturing.

\section{INTRODUCTION}

The aim of the modern technology of case hardening is to obtain repeatable, precisely planned parameters of a hardened layer, and to minimise the negative processes which bring about dimension changes following quenching, as well as to identify the nature and size of such changes $[1,2]$. Low-pressure carburizing followed by quenching is one of the methods by which this can be accomplished, but - along with a number of advantages - it has some weaknesses, which decrease its potential.

Although new technologies have been developed and implemented, there is one feature that has remained unchanged and common to these and the traditional technology: namely, that items are arranged on special equipment to form batches and they undergo the whole case hardening process in this configuration. This means that each item in a batch is affected by the process conditions in a manner unique to a given position, reaching parameters specific to the heating rate, composition of the process atmosphere and rate and direction of cooling. There is no doubt that items in outer layers of a batch are heated more quickly and that they reach a different temperature (according to the temperature distribution within a batch), the atmosphere around them is "richer" and they are quenched more intensely compared to the items within. This results in considerable dispersion of the results of a case hardening process in items inside the batch, e.g.: surface and core hardness, microstructure, and especially the effective case depth [3].

Basically, all the weaknesses and limitations of traditional thermal treatment can be attributed to its batch-related nature. Therefore, to open new perspectives, this factor should be eliminated and replaced with its opposite, i.e. a single-piece flow model. The single-piece flow concept in thermal 
treatment for mass production has been present in theoretical considerations, industry articles, lectures and presentations for some time [4, 5]. Various system solutions, more or less in line with the idea, have been developed, but no device for mass thermal treatment has been constructed so far that would embody the idea fully. Single-piece flow case hardening should be understood as the process in which every single item goes through identical positions and process conditions, like every item before and after it.

An analysis of the construction solutions applied so far in devices for thermal treatment of steel items has resulted in a new approach to the issue, which has not been described in the literature or proposed by any manufacturer of thermal treatment equipment in the world and which employs a furnace of a special construction (Fig. 1) [6, 7]. The new solution contains three parallel, connected technological chambers in which single items move in a stream; such chambers are arranged horizontally and placed in a common vacuum space with a gas leak-tight separation. The unloading lock is integrated with an individual gas cooling device in the furnace operation cycle, which can be easily connected further to an external tempering device. Therefore, each item passing through the process chambers with stabilised parameters will stay in identical process conditions $[8,9]$.

The experiment conducted for this study included preparation of a device for vacuum operation and work was launched aimed at developing and implementation in the device of a brand new technology of short-pulse low-pressure carburiz- ing, which would be optimal for this special furnace construction. The ability of the device to carry out short-pulse vacuum carburizing followed by high pressure gas quenching was examined; subsequently, uniformity, evenness and repeatability of the hardened case obtained was tested.

The device resulting from the experiment will be a fully robotised part of a production line which can be included in a system of automatic control of a production process.

\section{MATERIALS AND METHODS}

The concept of short-pulse low-pressure carburizing is derived from the FineCarb lowpressure carburizing technology, which has been properly documented in the literature [10-16]. The process in the FineCarb method is divided into a sequence of pairs of "boost-diffusion" segments. Items stay in a chamber with carboniferous gas during several-minute boost segments. The carboniferous gas is evacuated and items are held in technical vacuum during several-minute diffusion segments. There is only one pair of boost-diffusion segments in the short-pulse method, and the duration of both segments is the same. Carboniferous gas in injected repeatedly in short impulses, lasting a few seconds each.

Thirteen processes of short-pulse vacuum carburizing were conducted during the first phase of the experiment by the short-pulse method at temperatures ranging from 950 to $1050^{\circ} \mathrm{C}$ and with duration of the diffusion segment of 900 to

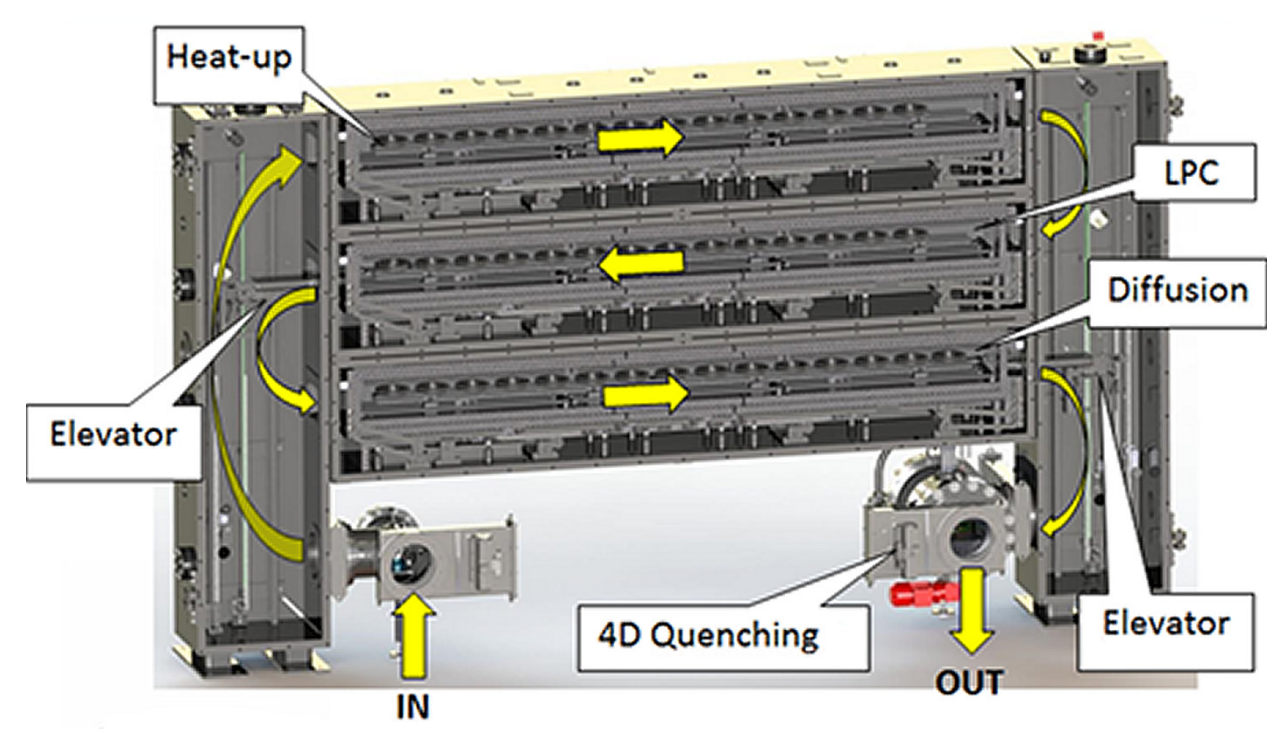

Fig. 1. The vacuum furnace for single-pieceflow case hardening 
1200 s and duration of carburizing gas injection of 5-30 s with a batch of gears with the diameter of $105 \mathrm{~mm}$, made of EN $20 \mathrm{MnCr} 5$ steel. After carburizing, the gears were quenched in gas and tempered in a separate device. Two wheels were treated in each process. They were subsequently taken for carbon and metallographic tests; the following were tested: surface hardness, tooth microhardness profile, hardness profiles at measurement points and carbon concentration profile. The aim of these preliminary tests was to demonstrate the operational readiness of the prototype, including carrying out the process of short-pulse low-pressure carburizing and high-pressure gas quenching. The results of the experiment have confirmed the operational capability and have confirmed that it is justifiable to pass on to the principal tests of quality, evenness and repeatability of the carburized layers.

The main experiment involved low-pressure carburizing at a temperature of $1000^{\circ} \mathrm{C}$, the carboniferous gas pressure of $\left(\mathrm{C}_{2} \mathrm{H}_{2}\right)$ of $3 \mathrm{hPa}$ and the flow rate of $7.5 \mathrm{~L} / \mathrm{min}$ on a batch of 25 gears with the diameter of $105 \mathrm{~mm}$, made of EN 20MnCr5 steel. The gears were subsequently quenched in nitrogen at a pressure of $0.5 \mathrm{MPa}$ for 35 seconds. Seven gears were sampled randomly from the entire batch and 4 fragments were cut out of each (at points corresponding to 3, 6, 9, 12 o'clock); the following tests were carried out: measurement of surface hardness, teeth microhardness profile, teeth microstructure, carbon concentration profile.

\section{RESULTS}

The surface hardness tests were performed for all samples. The average surface hardness of the gears was $62.3 \pm 1.0 \mathrm{HRC}$. Detailed results are shown in (Table 1). A distribution of hardness profiles on the gears is shown in (Fig. 2). The profiles for all the gears measured coincided.

The microstructure of the teeth, examined on the addendum, dedendum and flank of the teeth, is shown in (Fig. $3 \mathrm{a}-\mathrm{c}$ ). The carburized layers were found to be carburized uniformly and their microstructure was evaluated as correct for this process.

The results of concentration measurements in the hardened layers for three selected gears are shown in (Fig. 4-6). Carbon profiles measured at $3,6,9$ and 12 o'clock points were found to coincide in all the gears taken for the test.
Table 1. Tests of surface hardness of gears following thermo-chemical treatment

\begin{tabular}{|c|c|c|c|c|c|}
\hline \multicolumn{5}{|c|}{ Surface hardness [HRC] } \\
\hline \multirow{2}{*}{$\begin{array}{c}\text { Gear } \\
\text { no }\end{array}$} & \multicolumn{5}{|c|}{ "Hour” } \\
\cline { 2 - 6 } & 3 & 6 & 9 & 12 & \\
\hline 22 & 60.6 & 61.6 & 61.3 & 60.2 & 60.9 \\
\hline 25 & 62.6 & 62.2 & 63.8 & 63.1 & 62.9 \\
\hline 27 & 63.2 & 63.7 & 63.3 & 62.4 & 63.2 \\
\hline 28 & 62.5 & 63.0 & 62.8 & 62.5 & 62.7 \\
\hline 29 & 61.3 & 61.4 & 60.1 & 60.2 & 60.8 \\
\hline 30 & 61.4 & 64.2 & 64.1 & 62.3 & 63.0 \\
\hline 31 & 61.7 & 62.4 & 63.3 & 63.4 & 62.7 \\
\hline 34 & 64.0 & 63.0 & 63.2 & 63.6 & 63.5 \\
\hline 35 & 62.7 & 64.2 & 63.4 & 62.8 & 63.3 \\
\hline 36 & 59.6 & 63.1 & 61.1 & 60.2 & 61.0 \\
\hline 37 & 61.9 & 63.3 & 63.6 & 63.1 & 63.0 \\
\hline 38 & 63.1 & 64.4 & 63.7 & 62.3 & 63.4 \\
\hline 39 & 61.7 & 61.6 & 61.5 & 60.9 & 61.4 \\
\hline 41 & 61.7 & 62.0 & 62.0 & 62.9 & 62.2 \\
\hline 45 & 63.2 & 62.2 & 62.5 & 62.5 & 62.6 \\
\hline 47 & 62.7 & 61.9 & 63.1 & 63.2 & 62.7 \\
\hline 48 & 62.3 & 61.9 & 63.3 & 63.4 & 62.7 \\
\hline 49 & 59.9 & 60.1 & 60.7 & 59.6 & 60.1 \\
\hline 50 & 62.1 & 63.3 & 61.1 & 61.2 & 61.9 \\
\hline 52 & 60.4 & 60.9 & 59.9 & 62.6 & 61.0 \\
\hline 53 & 62.8 & 63.7 & 64.2 & 63.5 & 63.6 \\
\hline 54 & 62.5 & 62.7 & 64.4 & 63.0 & 63.2 \\
\hline 55 & 61.1 & 62.0 & 60.9 & 60.4 & 61.1 \\
\hline 56 & 62.4 & 63.2 & 63.4 & 63.0 & 63.0 \\
\hline 57 & 62.4 & 62.8 & 62.6 & 62.0 & 62.5 \\
\hline
\end{tabular}

\section{DISCUSSION}

The microstructure tests have shown that the layers are uniform and even. Moreover, layer uniformity is also confirmed by the carbon concentration profiles in the layers. Moreover, it was demonstrated in the testing of the bilateral hypothesis that there were no grounds for claiming that the average surface hardness deviates from the nominal value (62.3 HRC). This means that the surface hardness obtained in this experiment is repeatable.

These are the findings of a process carried out at the temperature of $1000^{\circ} \mathrm{C}$, at the time of one gear passing through the carburizing chamber of $\mathrm{t}=15 \mathrm{~min}$., the carboniferous gas 
Teeth hardness profiles

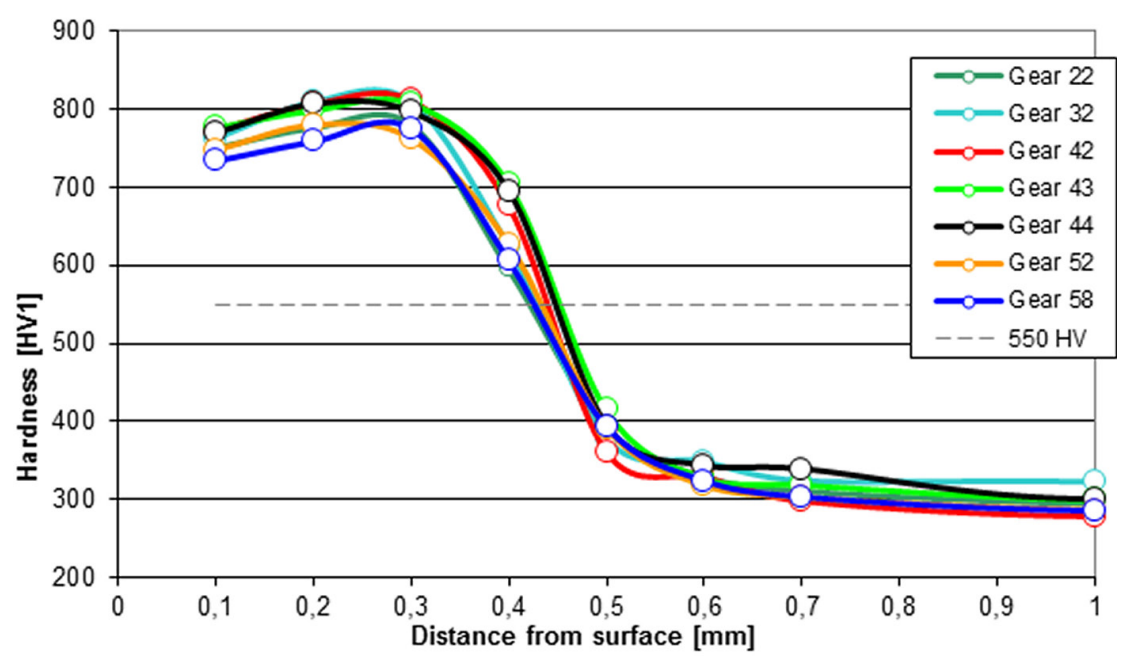

Fig. 2. Hardness profiles measured on gear teeth following treatment

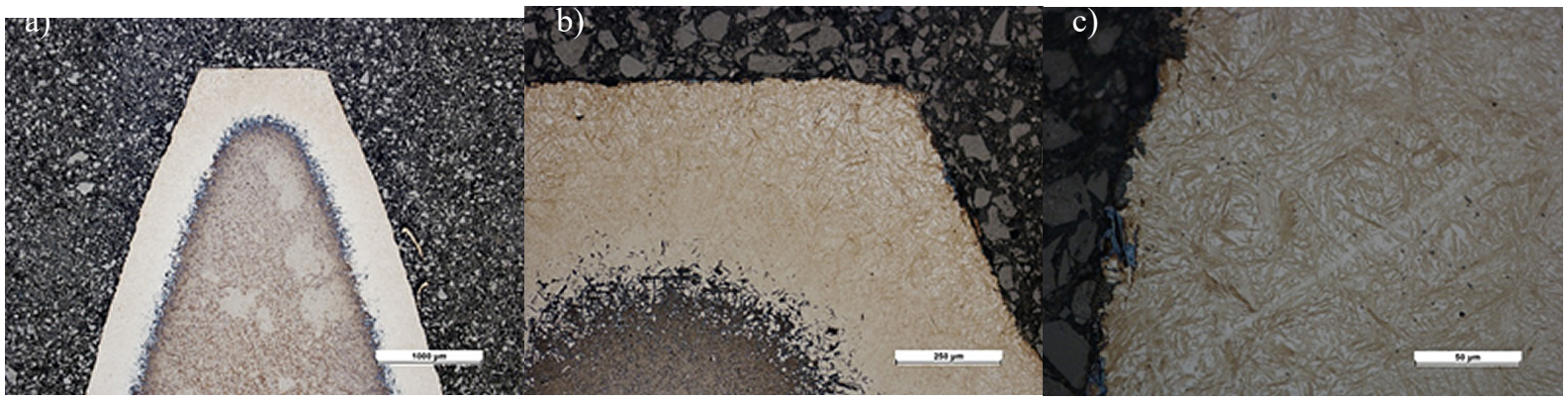

Fig. 3. Tooth microstructures following thermo-chemical treatment; a) gear 22, tooth, magnification x25; b) Gear 22, tooth corner, magnification x100; c) Gear 22, flank, magnification x500

\section{Gear no 22}

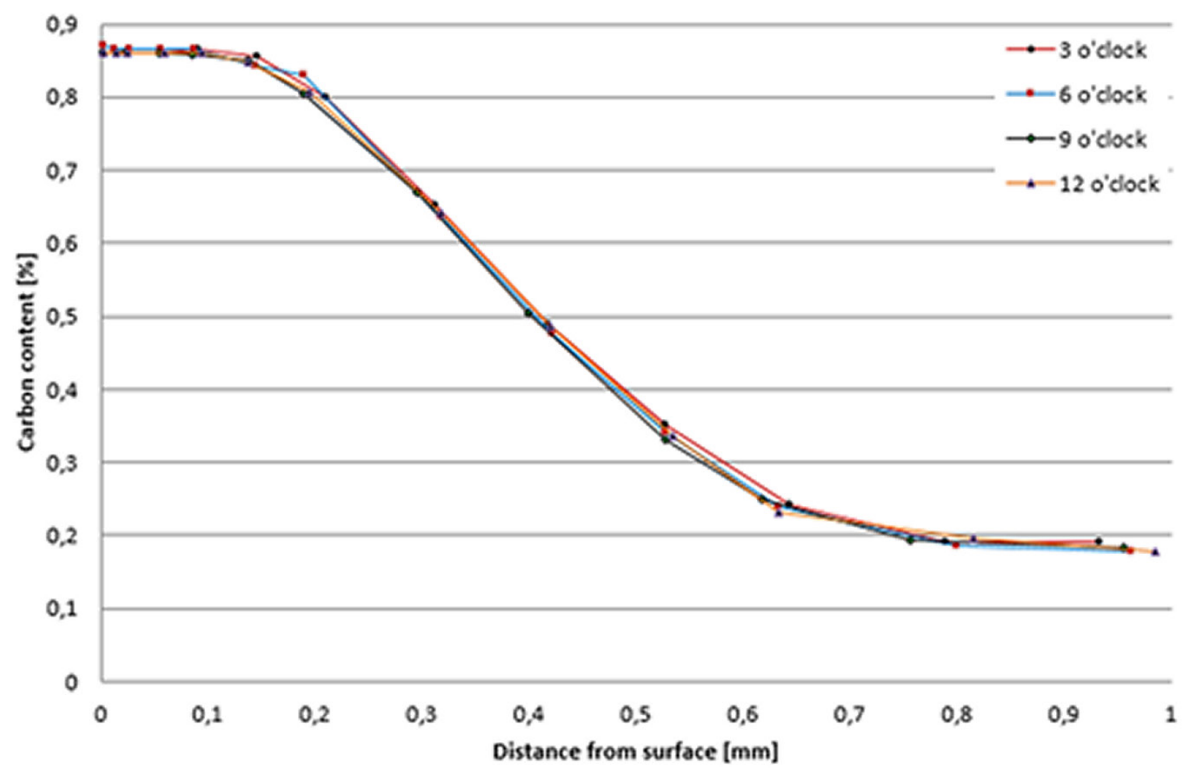

Fig. 4. Profile of carbon concentration distribution in the surface layer in gear no. 22 following carburizing (temp. $1000^{\circ} \mathrm{C}$ ) 


\section{Gear no 42}

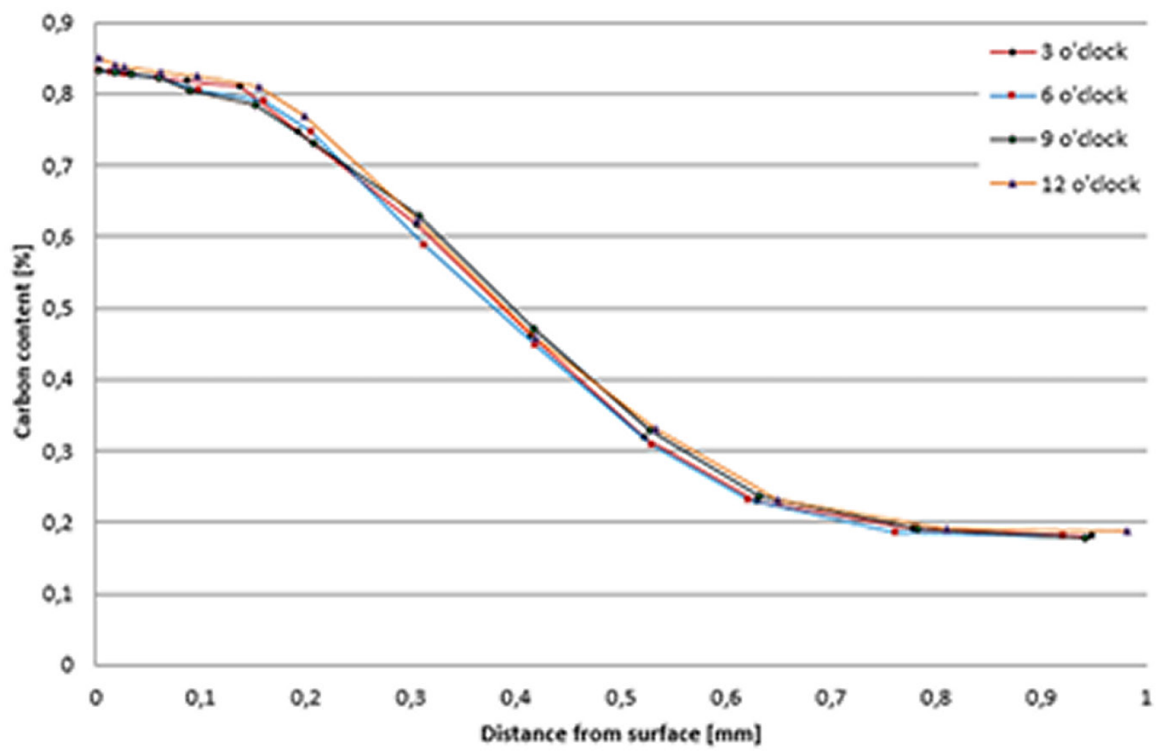

Fig. 5. Profile of carbon concentration distribution in the surface layer in gear no. 32 following carburizing (temp. $1000^{\circ} \mathrm{C}$ )

\section{Gear no 52}

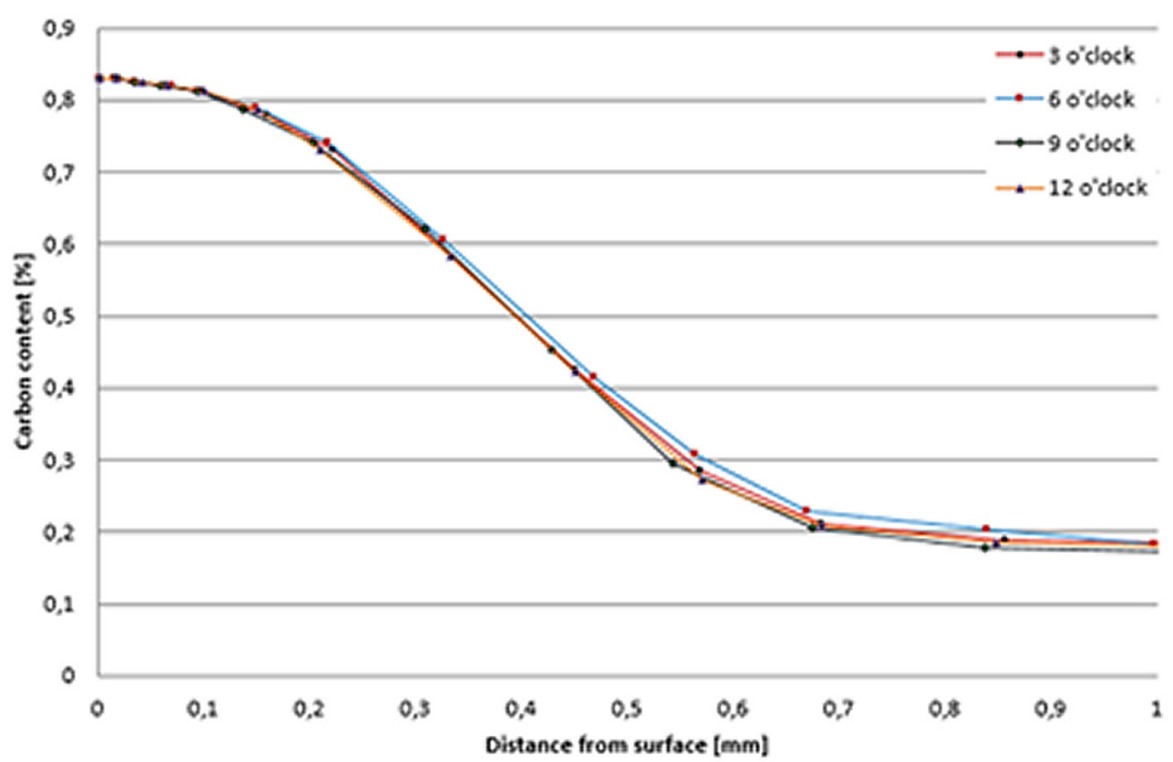

Fig. 6. Profile of carbon concentration distribution in the surface layer in gear no. 42 following carburizing (temp. $1000^{\circ} \mathrm{C}$ )

(acetylene) pressure of $3 \mathrm{hPa}$ and its flow rate of $7.5 \mathrm{~L} / \mathrm{min}$. Currently there are not enough data to determine whether it is the optimum (minimum sufficient) pressure and passing time for this process temperature and this batch size. It is advisable to carry out more studies in order to determine the optimum combinations of acetylene pressure and flow rate as a function of temperature, time and the batch surface area.

\section{CONCLUSIONS}

1. The device ability to carry out the process of short-pulse vacuum carburizing followed by high pressure gas quenching has been confirmed.

2. Uniformity and evenness of the hardened layers obtained by the treatment has been confirmed for the whole item surface.

3. Hardness of gears achieved in the process has been found to be repeatable. 


\section{Acknowledgments}

The research and publication were financed by the National Centre for Research and Development as part of project no. POIR.04.01.04-000087/15 entitled: "Equipment for high performance and precise heat treatment with a quenching deformation reduction system for direct application in downstream production chains of mechanical gearing and bearings".

\section{REFERENCES}

1. Gawroński Z., Malasiński A., Sawicki J. Elimination of galvanic copper plating process used in hardening of conventionally carburized gear wheels. International Journal of Automotive Technology, 11 (1), 2010, 127-131.

2. Gawroński Z., Sawicki J. Technological surface layer selection for small module pitches of gear wheels working under cyclic contact loads. Materials Science Forum, 513, 2006, 69-74.

3. Dybowski K., Sawicki J., Kula P., Januszewicz B., Atraszkiewicz R., Lipa S. The effect of the quenching method on the deformations size of gear wheels after vacuum carburizing. Archives of Metallurgy and Materials, 61 (2B), 2016, 1057-1062.

4. Heuer V., Löser K., Schmitt G. and Ritter K. One Piece Flow: Integration of Case Hardening into the Manufacturing Line. Proceedings of Conference on Gears, TUM Garching, Germany, 2010.

5. IHI. In-Line Heat Treatment - Next Generation Heat Treatment Equipment. IHI Engineering Review, 44 (2), 2011.

6. Korecki M., Wołowiec-Korecka E. and Glenn D. Single-piece, high-volume, low-distortion case hardening of gears. Proceedings of AGMA Fall Technical Meeting 2015, Detroit, USA, 2015.

7. Korecki M., Fujak W., Olejnk J., Stankiewicz M. and Wołowiec-Korecka E. Patent Application No
EP 16000164.0, 2016.

8. Korecki M. and Wołowiec-Korecka E. In-line, high-volume, low-distortion, precision case hardening for automotive, transmission and bearing industry. Proc. of $23^{\text {rd }}$ International Congress of Advanced Thermal Processing, Savanah, USA, 2016.

9. Korecki M., Wołowiec-Korecka E. and Brewka A. Unicase Master - In-line, high-volume, low-distortion, precision case hardening for automotive, transmission and bearing industry. Proceedings of 3rd International Conference on Heat Treatment and Surface Engineering in Automotive Applications, Prague, Czech Republic, 2016.

10. Kula P., Olejnik J. and Kowalewski J. FineCarb - The smart system for vacuum carburizing. Heat Treating \& Hardening of Gears, 3, 2004, 1-10.

11. Kula P., Pietrasik R. and Dybowski K. Vacuum carburizing - process optimization. Journal of Materials Processing Technology, 164-165, 2005, 876-881.

12. Kula P., Korecki M., Pietrasik R., Wołowiec E., Dybowski K., Kołodziejczyk Ł., Atraszkiewicz R. and Krasowski M. FineCarb - the flexible system for low pressure carburizing. New options and performance. Journal of The Japan Society for Heat Treatment, 49 (1), 2009, 133-136.

13. Korecki M., Olejnik J., Kula P., Pietrasik R. and Wołowiec E. Hornosc de vacio LPC+LPN+HPGQ 25 bar N2/He. Tratamientos termicos, 124, 2011, 17-21 (in Spanish).

14. Kula P., Dybowski K., Wołowiec E. and Pietrasik R. Boost-diffusion vacuum carburizing - process optimisation. Vacuum, 99, 2014, 175-179.

15. Korecki M., Kula P., Wołowiec E., Bazel M. and Sut M. Low pressure carburizing and nitriding of fuel injection nozzles. Heat Processing, 3, 2014, 59-62.

16. Wołowiec E., Kula P., Kołodziejczyk Ł., Dybowski K. and Korecki M. Mathematical modelling of the vacuum carburizing process. Thermal Processing for Gear Solutions, 3-4, 2014, 34-40. 